\title{
Contribuições da Abordagem Pikler para se Pensar a Inclusão na Creche: notas sobre a Formação de Professores de Educação Infantil
}

\author{
Contribuciones del Enfoque Pikler para Pensar la Inclusión en la \\ Guardería: notas sobre la Formación de Maestros de Educación Infantil \\ Contributions of Pikler's Approach to Thinking Inclusion in Nursery \\ School: notes on the Training of Early Childhood Teachers
}

\author{
Rafael Ferreira Kelleter ${ }^{1}$ \\ Rodrigo Saballa de Carvalho ${ }^{2}$
}

\begin{abstract}
Resumo
O trabalho parte do campo dos Estudos da Infância, objetivando evidenciar as contribuições da abordagem de Emmi Pikler para que se possa pensar a inclusão na creche e, de modo correlato, a formação docente. Metodologicamente, trata-se de uma pesquisa bibliográfica sobre a obra de Pikler, na qual se discute como bebês e crianças bem pequenas, através dos cuidados básicos, do vínculo, da figura de um adulto de referência, podem ter um processo exitoso de inclusão na creche. Além disso, o trabalho aponta a necessidade de que a formação docente leve em consideração as diferenças e individualidades dos bebês para que seja construída uma imagem de criança potente. Para tanto, são definidas três unidades de análise: 1) histórico da abordagem de Emmi Pikler e suas relações com os processos de inclusão na creche; 2) imagem de criança na abordagem Pikler e suas relações com os processos de inclusão; 3) princípios da abordagem Pikler e suas reverberações na formação de professores. A partir da pesquisa, é possível inferir a importância do respeito às temporalidades dos bebês e crianças pequenas, independentemente da sua condição, pois, em vez de estimular, é preciso prover espaços nos quais existam acolhimento e promoção de oportunidade de desenvolvimento.
\end{abstract}

Palavras-chave: Educação Infantil; creche; inclusão; abordagem Pikler; formação docente.

\section{Resumen}

Este trabajo se basa en los Estudios de la Infancia, objetivando evidenciar las contribuciones del enfoque de Emmi Pikler para que se pueda pensar la inclusión en la guardería y, de modo correlacionado, la formación del docente. Metodológicamente, se trata de una investigación bibliográfica sobre la obra de Pikler, en la que se discute cómo bebés y niños pequeños, a través de los cuidados básicos, del vínculo y de la figura de un adulto de referencia, pueden tener un proceso de éxito en la inclusión en la guardería. Además, el trabajo señala la necesidad de que la formación docente tenga en cuenta las diferencias e individualidades de los bebés para que se construya una imagen de niño capaz. Para ello, se definen tres unidades de análisis: 1) historial del enfoque de Emmi Pikler y sus relaciones con los procesos de inclusión en la guardería; 2) imagen de niño en el enfoque Pikler y sus relaciones con los procesos de inclusión; 3) los principios del enfoque Pikler y sus reverberaciones en la formación de profesores. Desde la investigación, se puede inferir la importancia del respeto a las temporalidades de los bebés y niños pequeños, independientemente de su condición pues, en lugar de estimular, es necesario proveer espacios donde haya acogida y se promueva oportunidad de desarrollo.

\footnotetext{
${ }^{1}$ Mestrando em Educação, na Linha de Pesquisa Estudos sobre Infâncias do PPGEDU/UFRGS; Porto Alegre, Rio Grande do Sul, Brasil; rafaelfkelleter@yahoo.com.br

${ }^{2}$ Doutor em Educação - UFRGS, Professor do Programa de Pós-Graduação em Educação -PPGEDU/UFRGS e do Curso de Pedagogia da FACED/UFRGS. Orientador na Linha de Pesquisa Estudos sobre Infâncias do PPGEDU/UFRGS; Porto Alegre, Rio Grande do Sul, Brasil; rsaballa@terra.com.br
} 
Palabras-clave: Educación Infantil; guardería; inclusión; Enfoque Pikler; formación docente.

\begin{abstract}
The work is based on the field of Childhood Studies, aiming to highlight the contributions of Emmi Pikler's approach in order to think about inclusion in nursery schools and, correlatively, teacher training. Methodologically, this is a bibliographical research on Pikler's work, which discusses how babies and toddlers, through basic care, bonding, the figure of an adult of reference, can have a successful inclusion process in the nursery school. In addition, the paper points out the need for teacher training to take into account the differences and individualities of the babies in the building of an image of a powerful child. To do so, three units of analysis are defined: 1) history of Emmi Pikler's approach and its relation with the processes of inclusion in nursery school; 2) child image in Pikler's approach and its relation with the inclusion processes; 3) principles of Pikler's approach and its reverberations in teacher training. From the research, it is possible to infer the importance of respecting the temporalities of babies and toddlers, regardless of their condition, because, instead of stimulating, it is necessary to provide spaces in which there is acceptance and the promotion of development opportunities.
\end{abstract}

Keywords: Early Childhood Education; nursery school; inclusion; Pikler's approach; teacher training.

\title{
1. Introdução
}

Este artigo resulta dos estudos do autor principal, por 2 anos, em um Curso de PósGraduação em Atendimento Educacional Especializado, focando em Educação Especial Inclusiva e aprendendo sobre o tema, e, por 5 anos, sobre a Abordagem de Emmi Pikler e sobre como esses dois temas podem dialogar entre si. Durante esse período de estudo sobre Pikler, o autor principal deste manuscrito teve a oportunidade de ir à Hungria conhecer o Instituto Pikler, além de estudar e aprofundar seu conhecimento acerca do desenvolvimento infantil de 0 a 3 anos.

Tendo como base os estudos teóricos sobre Educação Especial Inclusiva (BOATO, 2009; CARVALHO, 2012; BAPTISTA, 2015; MANTOAN, 2017; SILVA, 2018) e a abordagem Pikler (DAVID; APPEL, 2010; FALK, 2016, FEDER, 2014), busca-se um diálogo entre esses dois temas, tentando mostrar a importância dos cuidados, do vínculo, do adulto de referência e também da motricidade livre. Visa-se à construção da autonomia, sem distinção entre os sujeitos que são considerados público-alvo da Educação Especial Inclusiva e os que não o são, almejando de fato o respeito às diferenças e às potencialidades de cada indivíduo.

Neste artigo, pretendemos mostrar o olhar pikleriano sobre a deficiência e qual concepção de sujeito é utilizada pela abordagem para pautar sua prática e poder dialogar com a Educação Especial Inclusiva, além de pensar a formação de professores na Educação Infantil.

Não podemos continuar acreditando que um sujeito com alguma deficiência não possui potencialidades, que deve ser um sujeitado, sem autonomia, sem ser valorizado pelo 
que é e sem ser reconhecido enquanto pessoa. A partir desse diálogo, pretendemos mostrar as possibilidades que os estudiosos da abordagem Pikler têm buscado para trabalhar o sujeito de forma autônoma desde o seu desejo, respeitando seus tempos, seus ritmos e suas capacidades, sem acelerar ou tentar recuperar um "tempo perdido".

Como as propostas pedagógicas direcionadas a crianças de 4 a 6 anos são mais desenvolvidas e conhecidas, elas acabam sendo oferecidas para crianças de 0 a 3 anos, de maneira dirigida e, por vezes, rígida. Ou seja, é possível percebermos um intenso processo de escolarização precoce dos bebês e crianças bem pequenas desde a creche. Infelizmente, tal fato tem ocorrido em uma etapa da vida na qual os bebês precisam experimentar seu entorno com autonomia e liberdade de movimentos e avançar em suas relações táteis com os objetos, o espaço e as pessoas ao seu redor (FALK, 2016). Por essa razão, concordamos com Carvalho e Radomski (2017, p.43), quando afirmam que é preciso que sejam problematizadas as práticas docentes naturalizadas no exercício da docência na creche, ou seja, "a forma escolar, a dissociação entre o cuidar e o educar, a didática da transmissão, a pedagogia da submissão, as 'atividades pedagógicas' e as rotinas inflexíveis que inviabilizam os tempos" dos bebês. Sem dúvida alguma, a contribuição dos referidos autores, contribui indefectivelmente para pensarmos na perspectiva propedêutica de desenvolvimento que ainda orienta a prática docente com bebês em muitas instituições, nas quais a ideia de estímulo vem tornando-se um imperativo.

A partir da exposição da seção introdutória, convém esclarecer que o artigo está organizado em mais quatro seções. Na segunda seção, é desenvolvida uma discussão sobre os modos como vem sendo entendida a inclusão na contemporaneidade, bem como os efeitos da mesma na educação escolar. Na terceira seção do artigo, o foco de discussão são as contribuições da abordagem Pikler, para que efetivamente seja possível pensar em uma imagem de criança autônoma e competente desde a creche. Na quarta seção, são apresentadas as possibilidades de um fecundo diálogo entre a abordagem Pikler, e o que tem sido nomeado como desenvolvimento infantil lento ou diferente. Por fim, na última seção são apresentadas as considerações finais do artigo, compostas por algumas notas para que se possa pensar a formação de professores de Educação Infantil, tendo em vista a inclusão das crianças e o respeito às diferenças.

\section{Sobre inclusão}

Nossa sociedade está em constante processo de evolução e mudanças em todos os sentidos, e não poderia ser diferente no que diz respeito à educação e à forma de estarmos nos relacionando enquanto indivíduos que partilham ambientes coletivos comuns. Sendo assim, a 
inclusão ou a participação de toda a sociedade faz-se absolutamente necessária e precisa ser bastante incentivada e debatida. Quando mencionamos a inclusão, referimo-nos a diferenças, a aceitar as diferenças, não deficiências ou transtornos em específico, mas que todo sujeito é único e, por isso, diferente. Reiterando o argumento o argumento apresentado, Bateson (1976, p.345) argumenta que:

na história natural do ser humano vivente, a ontologia e a epistemologia não podem ser separadas. As suas convicções (frequentemente inconscientes) sobre o mundo que circunda determinarão o seu modo de ver e de agir, e este seu modo de sentir e de agir determinará as suas convicções sobre a natureza do mundo. O homem é, portanto, aprisionado em uma trama de premissas epistemológicas e ontológicas que, independentemente de sua veracidade ou falsidade, assumem para ele um caráter de parcial autoconfirmação.

Assim, o debate sobre a questão da Educação Inclusiva é hoje um fenômeno de retórica, como foi a integração escolar nos últimos 30 anos. Ao mesmo tempo que se trata de uma ideologia importada de países desenvolvidos, representando um alinhamento ao modismo, pois não temos lastro histórico na nossa realidade que a sustente, não podemos negar que, na perspectiva filosófica, a inclusão é uma questão de valor, ou seja, é um imperativo moral. Não há como questioná-la na perspectiva filosófica ou política, porque, na verdade, é uma estratégia com potencial para garantir o avanço necessário na educação especial brasileira.

Tradicionalmente, a história da educação especial no Brasil tem se dado de forma paralela ou independente dos movimentos da educação regular, por existir uma necessidade urgente de universalização do acesso. Essa meta deve ser traçada pelo sistema da educação geral, uma vez que uma escola popular, para uma sociedade com acentuada estratificação social, que pretende ser mais democrática, não poderá surgir enquanto existirem mecanismos tão efetivos de exclusão e seletividade social. Assim, a luta é por construir uma escola brasileira pública de melhor qualidade para todos e, ao mesmo tempo, garantir que as especificidades da população-alvo da educação especial sejam respeitadas.

Hoje, a realidade da educação de crianças e jovens com necessidades educacionais especiais no país caracteriza-se por, de um lado, haver um forte sistema marcado pelo assistencialismo filantrópico, com patrocínio difuso de várias instâncias do poder público, e, do outro, um sistema educacional fragilizado que vem sendo incitado a abrir espaço para a educação escolar dessa parcela da população.

Conforme aponta Silva (2002), cabe lembrar que a educação especial no Brasil está atualmente enquadrada no contexto do pensamento neoliberal, o qual sabemos jogar contra a corrente da inclusão social e escolar, buscando a privatização, no sentido de reforço ao que 
não é público, ao privado não lucrativo, ao chamado "terceiro setor", às "parcerias" com a sociedade civil, ao filantrópico, ao "não governamental", ou seja, a tudo que minimiza o papel do Estado e, como consequência, as ações de responsabilidade do poder público. Tal contexto representa, na atualidade, um razoável desafio para o avanço das políticas educacionais direcionadas a crianças e jovens com necessidades educacionais especiais em nosso país. Isso porque, de acordo com as discussões trazidas por Mantoan (2018, p.3):

o poder da definição de uma identidade, contudo, é uma arena em que grupos sociais, corporações, tipos de conhecimento se atracam para garantir privilégios, posições de cunho científico, filosóficos, bens de toda a natureza. Incluir, excluir decorrem dessa luta pelo poder de possuir o conceito, de demarcar seu território, de classificar, de comparar.

De acordo com o exposto, podemos avaliar que a inclusão é vista, hoje em dia, como o caso de pessoas que estão fora dos padrões aos olhos de muitos em nossa sociedade. Pensamos ainda de forma dicotômica: alunos típicos e atípicos, deficientes e normais, saudáveis e doentes. Deve-se salientar que o desenvolvimento e o crescimento não são homogêneos e tampouco lineares, não sendo indicado traçar comparações entre os sujeitos.

Coste (1992, p. 45) mostra que o desenvolvimento da criança se faz por impulsões locais, de maneira não unitária, mas segmentar e diversificada. Sendo assim, devemos levar em consideração as relações mantidas entre os diversos elementos do desenvolvimento, como, por exemplo, um progresso rápido no caminhar, o qual pode ser acompanhado de uma lenta evolução da higiene pessoal. Enfim, o desenvolvimento da criança não se realiza de modo regular e progressivo, mas por "saltos qualitativos" que se seguem a períodos de lenta maturação, sucedidos por rupturas, por revoluções.

Dessa maneira, ao se propor uma estratégia de ação pedagógica que vise ao desenvolvimento de aspectos que precisam ser trabalhados na criança, não se pode somente considerar sua idade cronológica; deve-se pensar em suas capacidades e necessidades momentâneas em cada aspecto do desenvolvimento (BOATO, 2009). Cada aspecto pode caminhar no seu ritmo, uns mais lentos e outros seguindo o curso esperado. De qualquer forma, devemos tratar essa criança como um sujeito capaz, potente, sem apressá-lo; contudo, reforçando sua atual etapa de desenvolvimento para que ele possa entrar na próxima etapa fácil e naturalmente, quando isso for possível.

\section{Sobre a abordagem de Emmi Pikler}

Emmi Pikler fez seus estudos em Viena, formando-se em Medicina, com interesse pelas áreas de Prevenção e Fisiologia. Quando trabalhava no Hospital Universitário, observou 
que as crianças da periferia sofriam poucos traumas e fraturas, mesmo brincando de formas que poderíamos cogitar como perigosas. O pronto-atendimento era procurado mais pelas crianças de famílias com maior poder aquisitivo, embora saíssem pouco de casa, por serem exageradamente protegidas. Isso fez com que Pikler pensasse que as crianças que podem se mover em liberdade e sem restrições são mais prudentes, por conhecerem melhor suas capacidades e limites. Nesse sentido, conforme destaca Falk (1994, p.18), Pikler:

não acreditava que o bebê tivesse necessidade da intervenção direta do adulto, de suas instruções, nem de seus exercícios para adotar, conservar, ou abandonar as diferentes posições do corpo, nem para mudar de posição, nem para deslocar-se, nem para aprender a colocar-se em pé e caminhar.

Nesse sentido, os preceitos da abordagem de Emmi Pikler, pediatra e ortopedista, a partir de suas experiências como médica de família e como diretora de um abrigo em Budapeste, Hungria, são: a valorização da atividade autônoma da criança, baseada em suas próprias iniciativas; a atenção às relações estáveis da criança, incluindo o valor a uma relação emocional privilegiada com uma pessoa em especial; o oferecimento constante de possibilidades à criança para desenvolver a consciência sobre si mesma em seu ambiente; e a manutenção de um bom estado de saúde física da criança, o qual é base e, ao mesmo tempo, consequência dos princípios precedentes. Já na época, suas ideias eram vistas como revolucionárias e, ainda hoje, podem causar, de início, um certo estranhamento quando afirma que não devemos ensinar a criança a sentar, andar ou brincar, pois é muito melhor para seu desenvolvimento que ela descubra por si mesma como fazer isso.

Se consideramos o bebê como um ser competente e com potencial para se relacionar desde o nascimento, e não um ser passivo, apto apenas para receber o que o adulto oferece, é essencial estabelecermos com ele, desde o início de sua vida, uma relação de confiança e colaboração. Nesse sentido, de acordo com David e Appell (2010, p.120), abordagem Pikler:

\begin{abstract}
o tempo dedicado aos cuidados representa o melhor momento para um encontro privilegiado, quando o vínculo afetivo pode ser construído e aprofundado. Isso se torna mais fácil se um educador de referência cuida sempre do mesmo bebê (ou variando o menos possível) e se o bebê é chamado a participar dos momentos de cuidados, como troca de fraldas e de roupas, banho, alimentação e preparação para o sono. Dessa forma, o adulto pode fornecer a envoltura e a sustentação necessárias para o desabrochar de seu psiquismo.
\end{abstract}

A partir do exposto, entendemos a necessidade de regularidade de tempo e espaço para que o sentimento de segurança do bebê seja favorecido, e as tarefas de cuidar devem ser feitas com atenção e dedicação, respeitando os tempos dos bebês. O educador tem que dispor de tempo suficiente para que o bebê aproveite bem a experiência, desfrutando de cada gesto de cuidado que receber. Quando o educador narra o que faz e vai nomeando as partes do corpo 
sendo tocadas durante os cuidados, ajuda o bebê a construir seu esquema corporal, que é a experiência imediata da unidade dos segmentos do corpo e a posição que ele ocupa no espaço. O esquema corporal resulta da organização cognitiva e afetiva de cada um, sendo construído e reconstruído pelas contínuas alterações da posição do corpo no espaço. Ele favorece a aquisição das habilidades motoras.

A função tônica da musculatura é ligada à vida afetiva original do bebê e é por meio da vivência tônica que ele se conecta com o mundo. O tônus muscular é a qualidade de tensão involuntária que expressa as emoções e, nesse sentido, é uma forma de relacionamento. Os movimentos expressivos que traduzem conforto ou desconforto, satisfação ou demanda, prazer ou desprazer, vão se moldar, criando um código corporal em consequência das reações positivas ou negativas (DAVID; APPEL, 2010). O contato com vínculo gera segurança e percepção do próprio corpo do bebê e tem um profundo impacto sobre o tônus.

Dessa forma, um vínculo de confiança, de segurança afetiva (CHOKLER , 2017), será a sustentação para o desenvolvimento de um sujeito seguro de si mesmo, que pode se expressar com competência e procurar respostas a suas indagações, porque foi escutado em suas necessidades.

Para que haja um verdadeiro encontro entre a criança e o educador, é preciso que as atitudes e as palavras do adulto correspondam aos seus sentimentos. É fundamental que os educadores sejam coerentes entre o que dizem e manifestam para promover o desenvolvimento da autoconfiança e a possibilidade de a criança evoluir em seu potencial expressivo e nas interações interpessoais (SOARES, 2017).

Compreendendo a importância do vínculo e o momento dos cuidados como privilegiados para estabelecerem esse laço imprescindível para o desenvolvimento infantil sadio, resta-nos refletir sobre como podemos estabelecer um contato mais próximo com cada uma das crianças no ambiente coletivo, como, por exemplo, uma sala de aula.

\section{Desenvolvimento lento ou diferente: diálogos entre inclusão e abordagem Pikler}

O que entendemos por desenvolvimento lento não sugere muito, assim como o que entendemos por precocidade no desenvolvimento. Diante disso, poderíamos fazer perguntas do tipo: “O que é 'normal'?" ou "Quando se pode falar de desenvolvimento atípico, atrasado ou lento?".

Falk (2016) coloca que esse desenvolvimento lento ou diferente pede que se levem em consideração as características individuais e também os estágios de desenvolvimento da criança em cada área específica, pois duas crianças com o mesmo quadro podem apresentar 
comportamentos totalmente diferentes em relação ao seu desenvolvimento. Durante o desenvolvimento infantil, todas as aquisições mostram uma grande diversidade no que se refere aos detalhes e à idade de sua manifestação, e o reconhecimento dessa diversidade é indispensável para avaliar um fenômeno de desenvolvimento. Isso é mais facilmente aceito com relação ao crescimento somático do que com outras áreas do desenvolvimento.

Por muitos anos, a abordagem para atuar com pessoas com deficiência esteve influenciada por uma concepção mecanicista que visava reparar funções, ou ainda com ideias ortopédicas, de reabilitação, ligadas a um certo desempenho. Essas ideias emergiam tanto dos profissionais como das famílias, pela angústia da alteração genética, congênita ou perinatal, bem como pelo escândalo da deficiência e seus fantasmas de incompletude, pelo terror das marcas não reparáveis, do fracasso, do destino incerto, ou pela vivência do castigo que transforma aquilo que deveria ser maravilhoso em algo sinistro. Nesse sentido, ratificando o argumento apresentado, Beneito (2009, p.3) argumenta que:

não existe possibilidades de introjetar isso que vem do outro e relacioná-lo comigo e com o que sinto se não existe o compartilhamento emocional, a ressonância tônica necessária que não se dá somente na ficção, mas que resulta ser a base fundante da organização psicomotora das crianças com grandes patologias neurológicas. $\mathrm{O}$ momento do banho por exemplo resulta ser um condensador de situações relacionais: olhar, tato, sustentação, palavra, espera, alternâncias, ritmos, respostas, mímica, compreensão, entre outras.

A partir da contribuição do autor questionamos: - Como podemos pensar em uma forma diferente desse olhar que arrasta um projeto de família marcado pela dependência, pelo temor ao futuro, pela dificuldade para identificar-se com o outro? Esse projeto muitas vezes nem merece ser considerado, pois carrega tudo de ruim na visão de quem não está aberto às possibilidades desses sujeitos, e ainda conduz a uma estereotipia, à rigidez dos vínculos, à desorganização emocional e à ruptura da família.

As ideias de Pikler, em um primeiro momento, podem parecer duvidosas para pormos em prática com pessoas com deficiência. Há a possibilidade de questionamentos como, por exemplo, "O que pode fazer uma pessoa com deficiência sem a intervenção de alguém?" e "O que um bebê com deficiência pode fazer?".

O trabalho de acompanhamento que buscamos fazer, a partir da Abordagem Pikler, com crianças com deficiência é romper com o estigma de uma família que se encontra em um círculo vicioso, de maior rechaço e, portanto, maior negação e maior falta de resposta por parte da criança, o que exigirá maior estimulação para o seu desenvolvimento.

Conhecemos muitas linhas de tratamento que se baseiam no tato, no toque e insistem em sua importância. Pikler não nega a importância da pele como fronteira, como limite entre 
o interior e o exterior, como elemento relacional fundante, o que nos leva a quem, como e quando tocar, porém como destaca Feder (2006, p.35), a referida autora defende que:

a atividade autônoma é uma necessidade, desde a mais tenra idade. Descobrir o mundo a partir da própria curiosidade, da própria vontade de compreender e até de experimentar constitui o centro da vida cotidiana de um bebê. A motricidade livre oferece os meios para isso.

Em oposição a atividade autônoma, muitos acreditam que fazer a criança realizar exercícios correspondentes a determinado estágio de desenvolvimento facilitará ou acelerará esses processos, ou seja, trará um rápido acesso ao estágio considerado superior. Porém, o condicionamento, o treinamento e o adestramento voltados a atingir habilidades que ultrapassem a maturidade física ou psíquica têm um valor bastante duvidoso. Além do valor duvidoso dessa visão educacional propedêutica, destacamos que a mesma posiciona a criança em uma posição de fragilidade e incompetência, limitando consideravelmente a potencialidade da mesma em desenvolver-se no seu tempo e a partir das relações que estabelece consigo, com seus pares e com o entorno.

Por outro lado, como tudo está relacionado, tudo tem repercussão. As intervenções diretas, no que se relaciona ao atraso ou ao desvio, sem considerar o conjunto do processo do desenvolvimento somático, psicomotor, psicossocial e afetivo, correm o risco de desorganizar o equilíbrio existente. Isso porque como destaca Falk (2016, p.44):

quando existe falta de maturidade, a qualidade de execução é pior e, pela mesma razão, a criança se habitua às posturas e atividades que não domina, nem controla. A criança não dispõe de meios para aperfeiçoar por ela mesma, nem seu precário equilíbrio, nem a quantidade inadequada de atividade imposta.

O dito pela autora, nos possibilita inferir que crianças com necessidades especiais demonstram diferenças importantes em relação ao nível de desenvolvimento alcançado quanto à natureza e à gravidade de seus atrasos. Portanto, para que essas crianças possam desfrutar de um clima favoravelmente terapêutico, é preciso idealizar tarefas especiais e diferentes, de acordo com as situações e a personalidade de cada criança. Isso porque, como nos lembra Chokler (2017, p.26), é na "pedagogia da vida com os outros, pelos outros e contra os outros, que se aprende a ser e a fazer". Nesse contexto, é preciso pensar a educação das crianças para além das classificações, dos rótulos e das nomeações, que as impedem de desenvolverem-se enquanto sujeitos competentes.

\section{Considerações finais: algumas notas para pensar a formação docente}


O investimento na construção do vínculo afetivo, principalmente durante os cuidados, é um dos pontos que deve ser considerado como uma das contribuições de Emmi Pikler (FALK, 2011, 2016) para formação docente. Tendo um relacionamento seguro com o adulto, o bebê vai se conectando consigo, com o outro e com o mundo externo. Essa segurança vai se fortalecendo e favorecendo o movimento com liberdade, assim como as experiências posturais por iniciativa própria, procurando desenvolver o sujeito como um todo. Tal pressuposto pikleriano, sem dúvida alguma, contribui para a construção de uma outra imagem de bebê (independente do tipo de desenvolvimento do mesmo) e o entendimento de que "cada pessoa desde o nascimento é um ser completo, aqui e agora, construtor ativo de suas relações em cada uma de suas etapas de desenvolvimento e não um objeto passivo" (CHOKLER, 2017, p.31).

Nesse sentido, a abordagem de Emmi Pikler estabelece um diálogo com os pequenos detalhes do cotidiano dos bebês e crianças pequenas, apresentando maneiras que proporcionam a busca pelo mover-se através do desejo próprio. Assim, ocorre a apropriação pelo bebê dessa motricidade, desse corpo e do seu entorno.

Não é papel do adulto distrair a criança dela mesma, ou ficar excitando a criança como um animador de festa. É do "prazer de sentir e fazer que a criança constrói a sua competência para pensar" (CHOKLER, 2017). Por essa razão, deve-se levar em consideração as necessidades das crianças para então refletir sobre o cotidiano e suas práticas. Uma pedagogia dos detalhes que pauta sua prática no respeito aos tempos, nos cuidados básicos, no vínculo de apego seguro, na autonomia e na motricidade livre merece ocupar um lugar nas discussões sobre o cotidiano escolar e o currículo na educação infantil e, sobretudo, nos diálogos com a Educação Especial Inclusiva, pois pode contribuir muito para reflexões e a ressignificação de práticas pedagógicas.

Em tal perspectiva, concordamos com Carvalho e Radomski (2017, p.55) quando afirmam que "é necessário que seja reconhecida a especificidade da docência com bebês e a valorização do aprender pela vida cotidiana", já que a creche enquanto espaço de vida coletiva tem um papel social e político de receber, acolher e de prover os recém chegados ao mundo. Dessa maneira, talvez consigamos harmonizar nossas práticas de Educação Infantil sem acelerar processos e considerarmos as questões de construção de currículos para essa etapa da vida. Eis o desafio que propomos para a formação docente. 


\section{Referências}

BAPTISTA, C. R. (Org.). Inclusão e escolarização: múltiplas perspectivas. Porto Alegre: Mediação, 2015.

BATESON, G. Verso un'ecologiadella mente. Milano: Adelphi, 1976.

BENEITO, N. Emmi Pikler y la discapacidad. Disponível em: 〈https://www.piklerloczy.org/sites/default/files/documentos/noemi_beneito_emmi_pikler_y_1 a_discapacidad.pdf>. Acesso em: abr. 2018.

BOATO, E. M. Henri Wallon e a deficiência múltipla, uma proposta de intervenção pedagógica. São Paulo: Edições Loyola, 2009.

CARVALHO, R. E. Escola Inclusiva: a reorganização do trabalho pedagógico. 5. ed. Porto Alegre: Mediação, 2012.

CARVALHO, R. S.; RADOMSKI, L. L. Imagens da docência com bebês: problematizando narrativas de professoras de creche. Série-Estudos, Campo Grande, MS, v. 22, n. 44, p. 41-59, jan./abr. 2017. ISSN 2318-1982. Disponível em: http://www.serieestudos.ucdb.br/index.php/serie-estudos/article/view/1015. Acesso em: 10 jul. 2018.

COSTE, J. C. A Psicomotricidade. 4. ed. Rio de Janeiro: Guanabara Koogan, 1992.

CHOKLER, M. H. La aventura dialógica de la infancia. Buenos Aires: Cinco, 2017.

DAVID, M.; APPEL, G. Lóczy, una insólita atención personal. Barcelona: Octaedro, Rosa Sensat, 2010.

FALK, J. (Org.). Abordagem Pikler: educação infantil. 2. ed. São Paulo: Ominisciencia, 2016.

FALK, J. (Org.). Educar os Três Primeiros Anos, a experiência de Lóczy. 2. ed. Araraquara, SP: Junqueira \& Marin, 2011.

FEDER, A. S. Una mirada adulta sobre el niño en acción: el sentido del movimiento en la protoinfancia. Buenos Aires: Cinco, 2014.

MANTOAN, M. T. E. Inclusão, diferença e deficiência: sentido, deslocamentos, proposições. Inclusão Social, Brasília, v. 10, n. 2, p. 37-46, jan./jun. 2017.

SILVA, S. Exclusão do público, inclusão do privado: a terceirização dos serviços na educação especial. In: REUNIÃO ANUAL DA ANPED, 24., 2001, Caxambu. Anais... Caxambu: ANPED, 2001. Disponível em: <http://24reuniao.anped.org.br/T1581999935652.doc>. Acesso em: abr. 2018.

SOARES, S. M. Vínculo, movimento e autonomia: educação até 3 anos. São Paulo: Ominisciencia, 2017. 